\title{
Nanocrystallinity as a Route to Metastable Phases: Rock Salt ZnO
}

\begin{tabular}{|r|l|}
\hline Journal: & Chemistry of Materials \\
\hline Manuscript ID: & cm-2013-00293j.R1 \\
\hline Manuscript Type: & Article \\
\hline Date Submitted by the Author: & 01-Apr-2013 \\
\hline Complete List of Authors: & $\begin{array}{l}\text { Baranov, Andrey; Moscow State University, Chemistry Department } \\
\text { Sokolov, Petr; LSPM-CNRS, Université Paris Nord, } \\
\text { Tafeenko, Viktor; Moscow State University, Chemistry Department, } \\
\text { Lathe, Christian; Helmholtz-Zentrum Potsdam, } \\
\text { Zubavichus, Yan; RRC, Kurchatov Center for Synchrotron Radiation and } \\
\text { Nanotechnology } \\
\text { Veligzhanin, Alexey; RRC , Kurchatov Center for Synchrotron Radiation and } \\
\text { Nanotechnology } \\
\text { Chukichev, Mikhail; Moscow State University, Physics Department, } \\
\text { Solozhenko, Vladimir ; Universite Paris Nord, LSPM-CNRS }\end{array}$ \\
\hline \multicolumn{2}{|l}{} \\
\hline
\end{tabular}

\section{SCHOLARONE ${ }^{m}$}

Manuscripts 


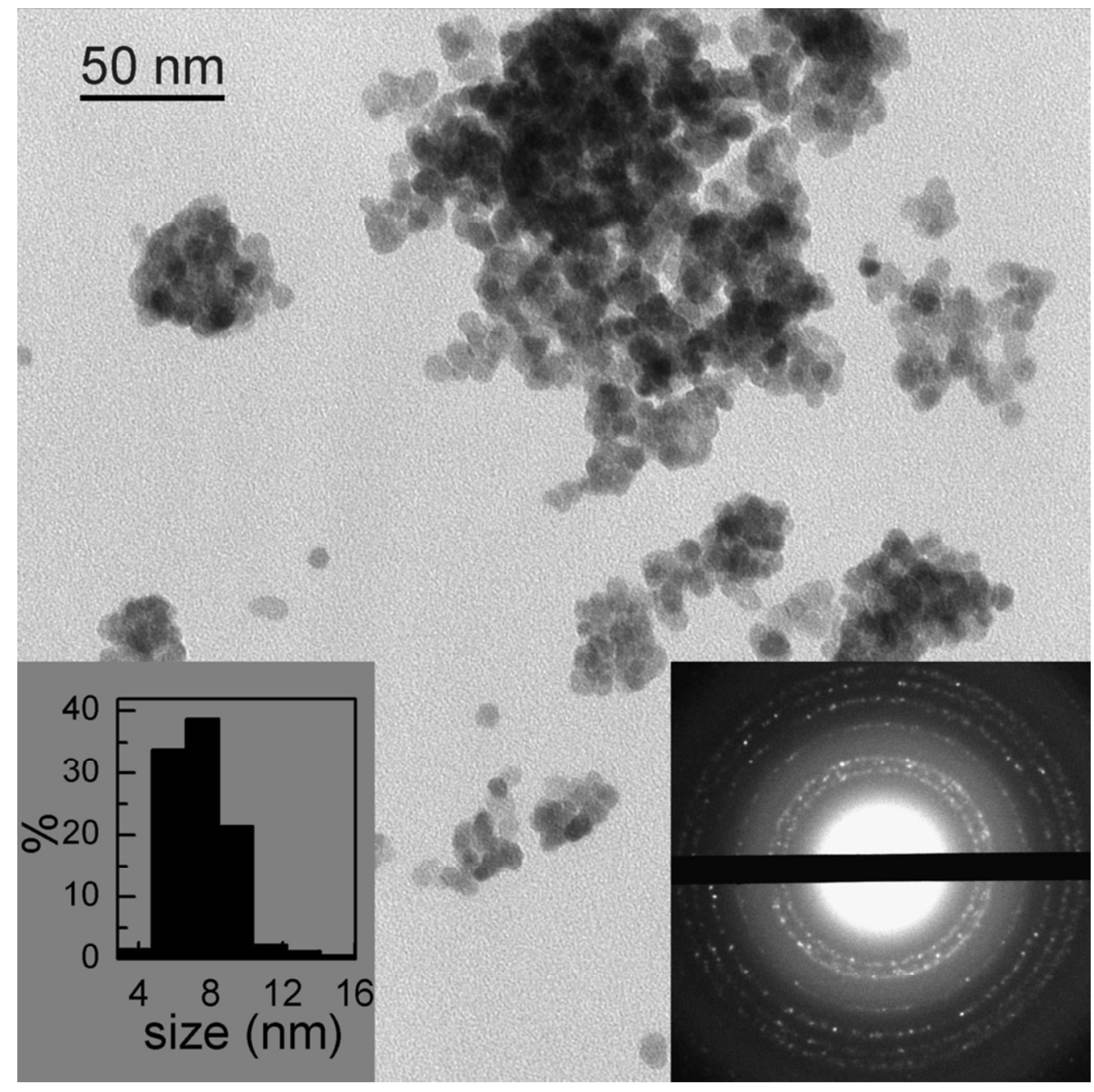

$86 \times 86 \mathrm{~mm}(300 \times 300$ DPI $)$ 


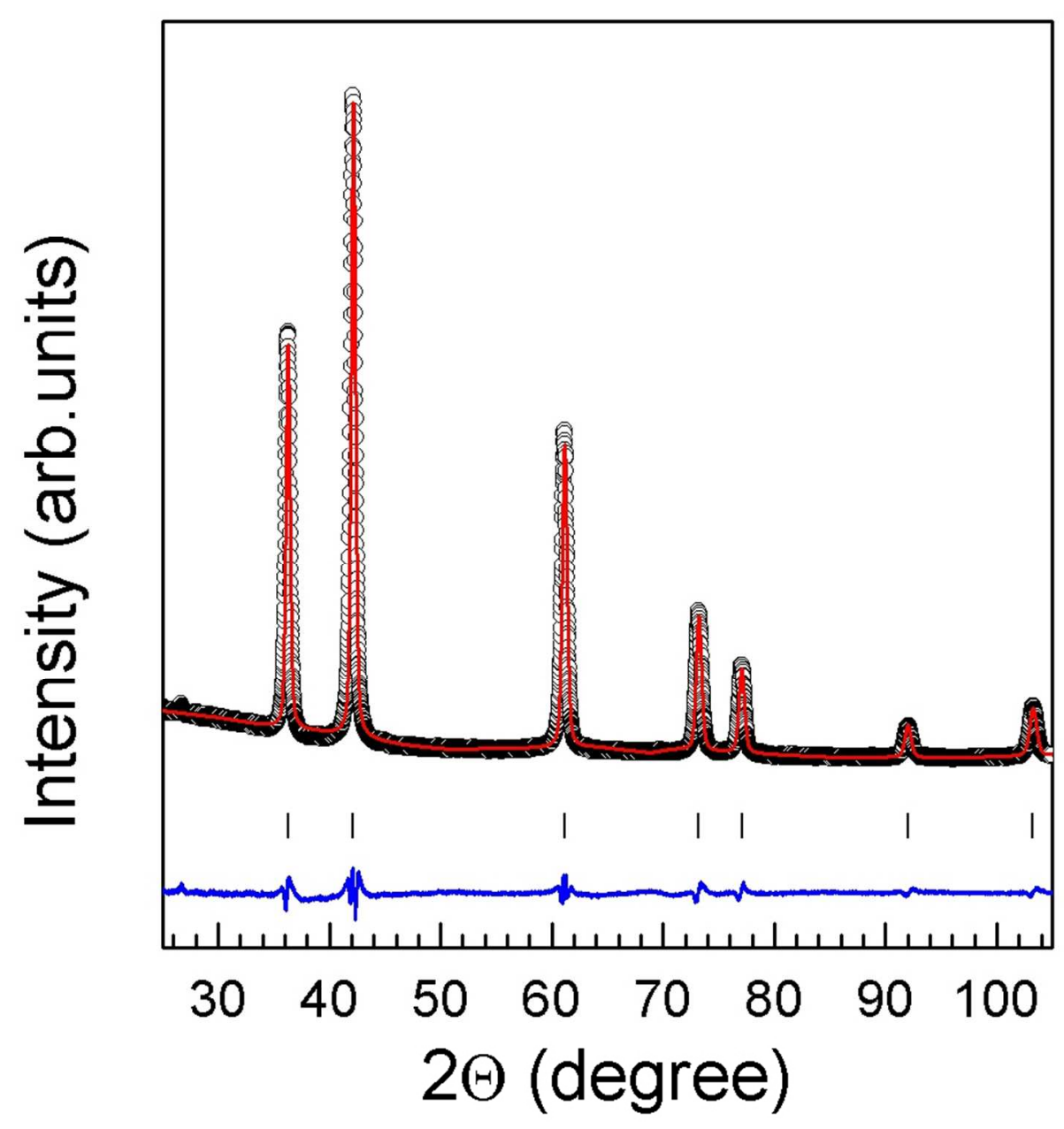

$84 \times 84 \mathrm{~mm}(300 \times 300 \mathrm{DPI})$ 


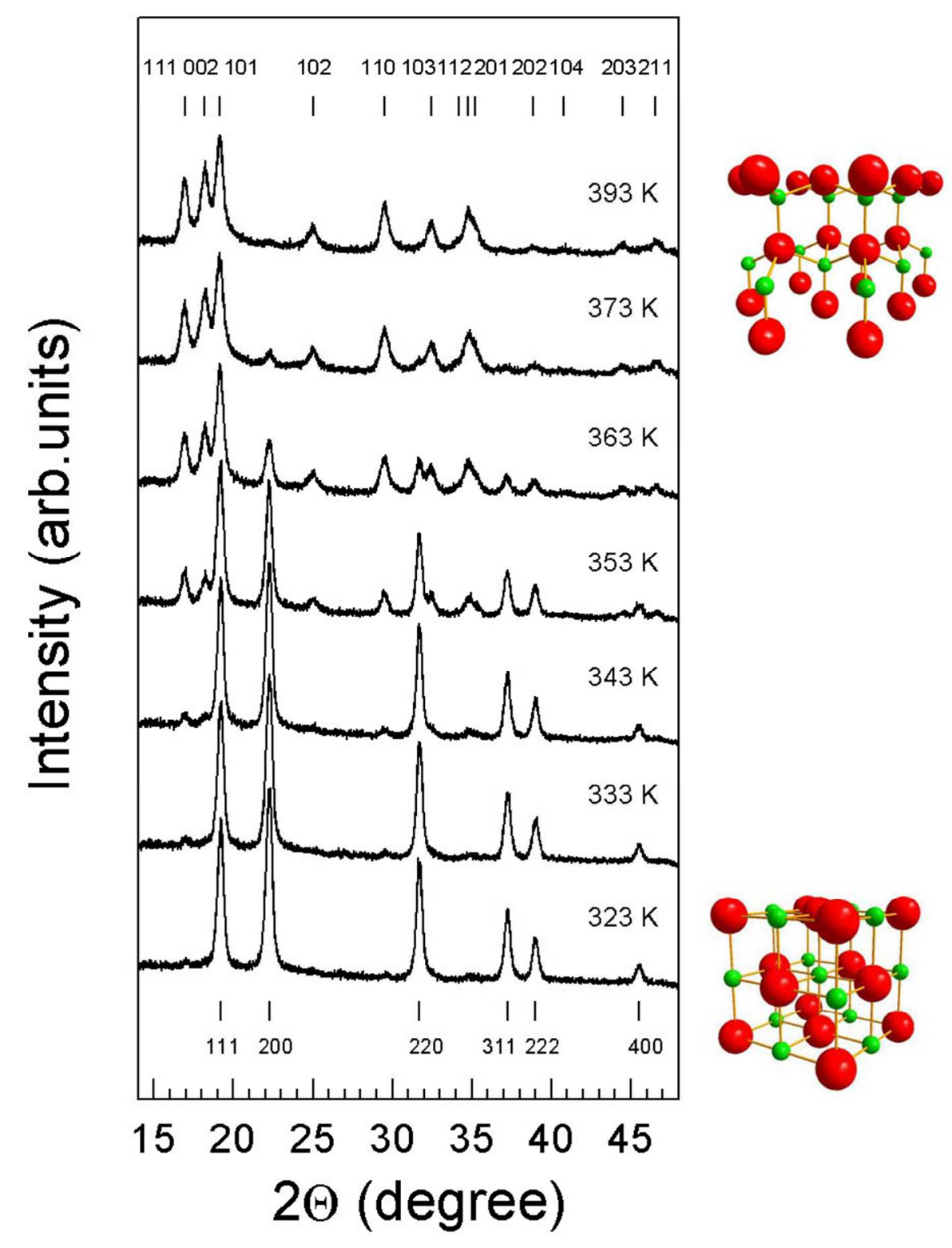

$84 \times 103 \mathrm{~mm}(300 \times 300$ DPI) 


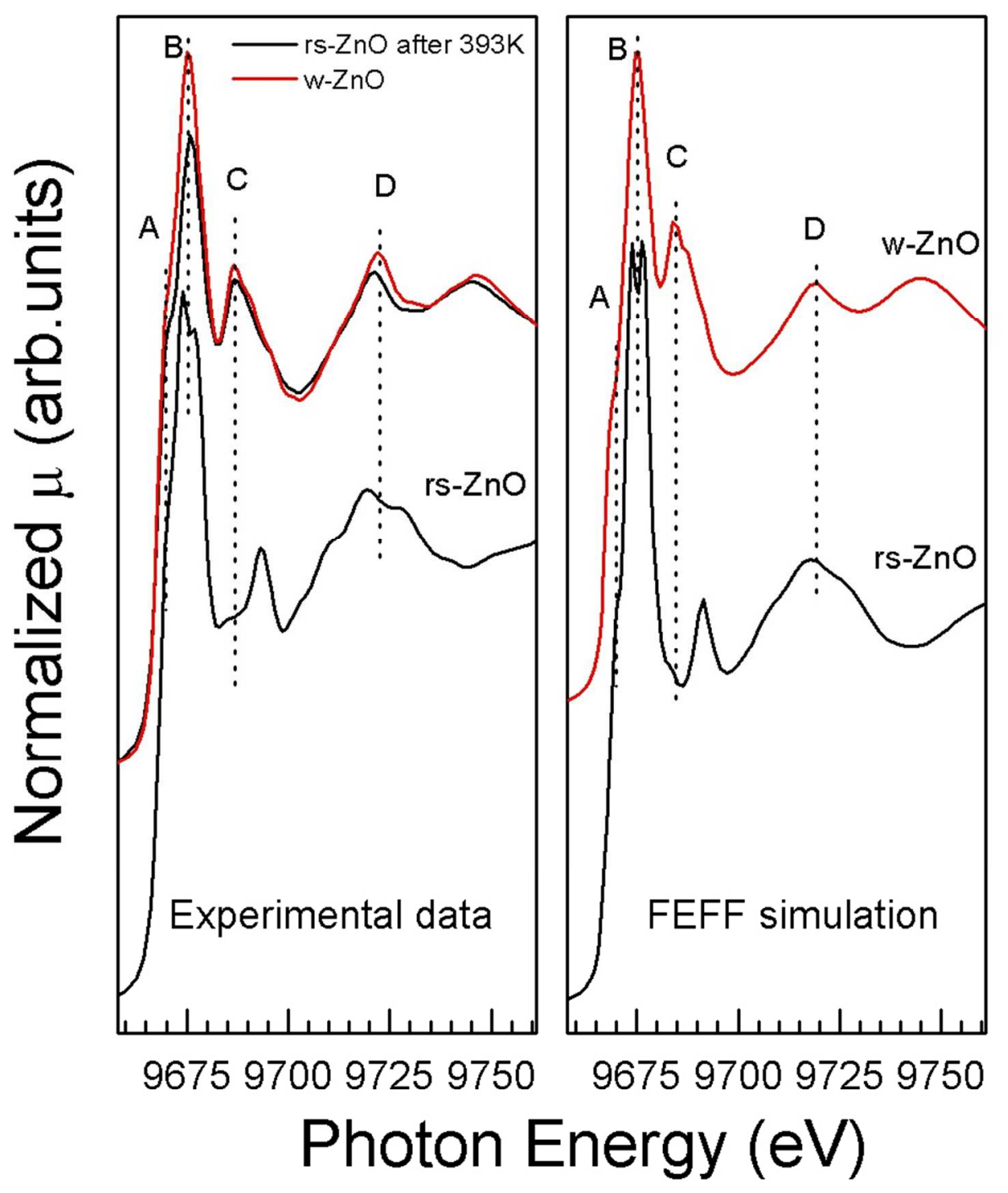

$84 \times 96 \mathrm{~mm}(300 \times 300$ DPI $)$ 

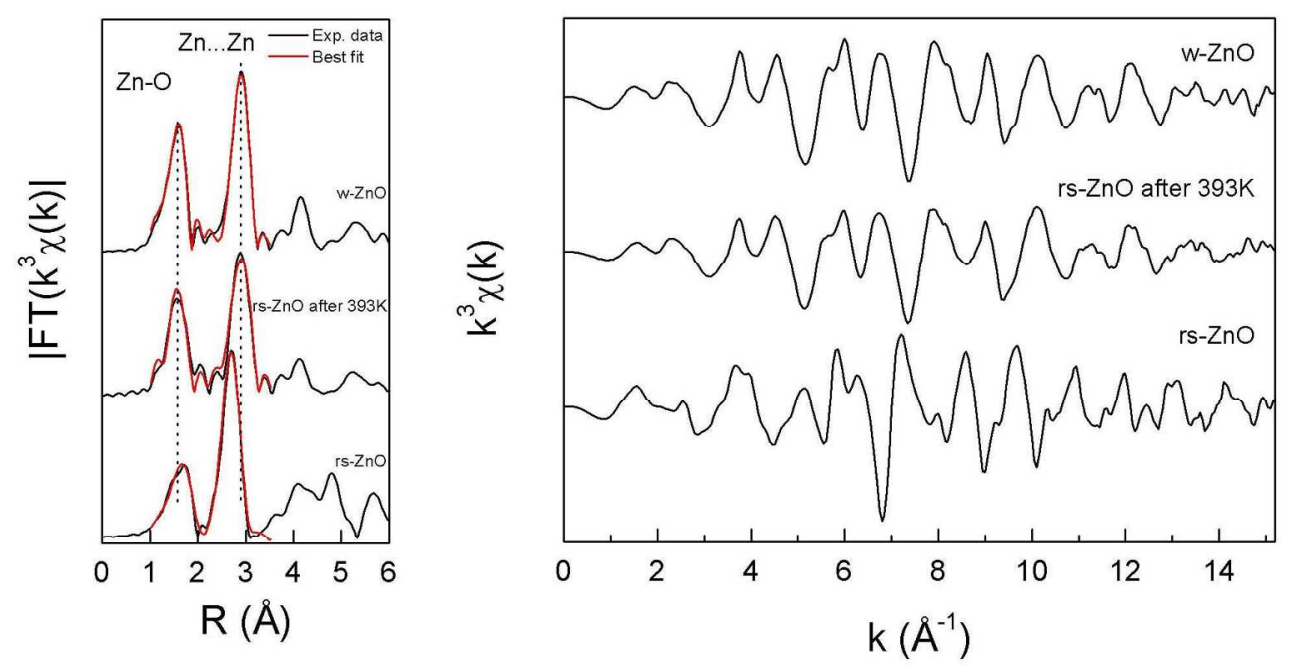

$169 \times 89 \mathrm{~mm}(300 \times 300 \mathrm{DPI})$ 


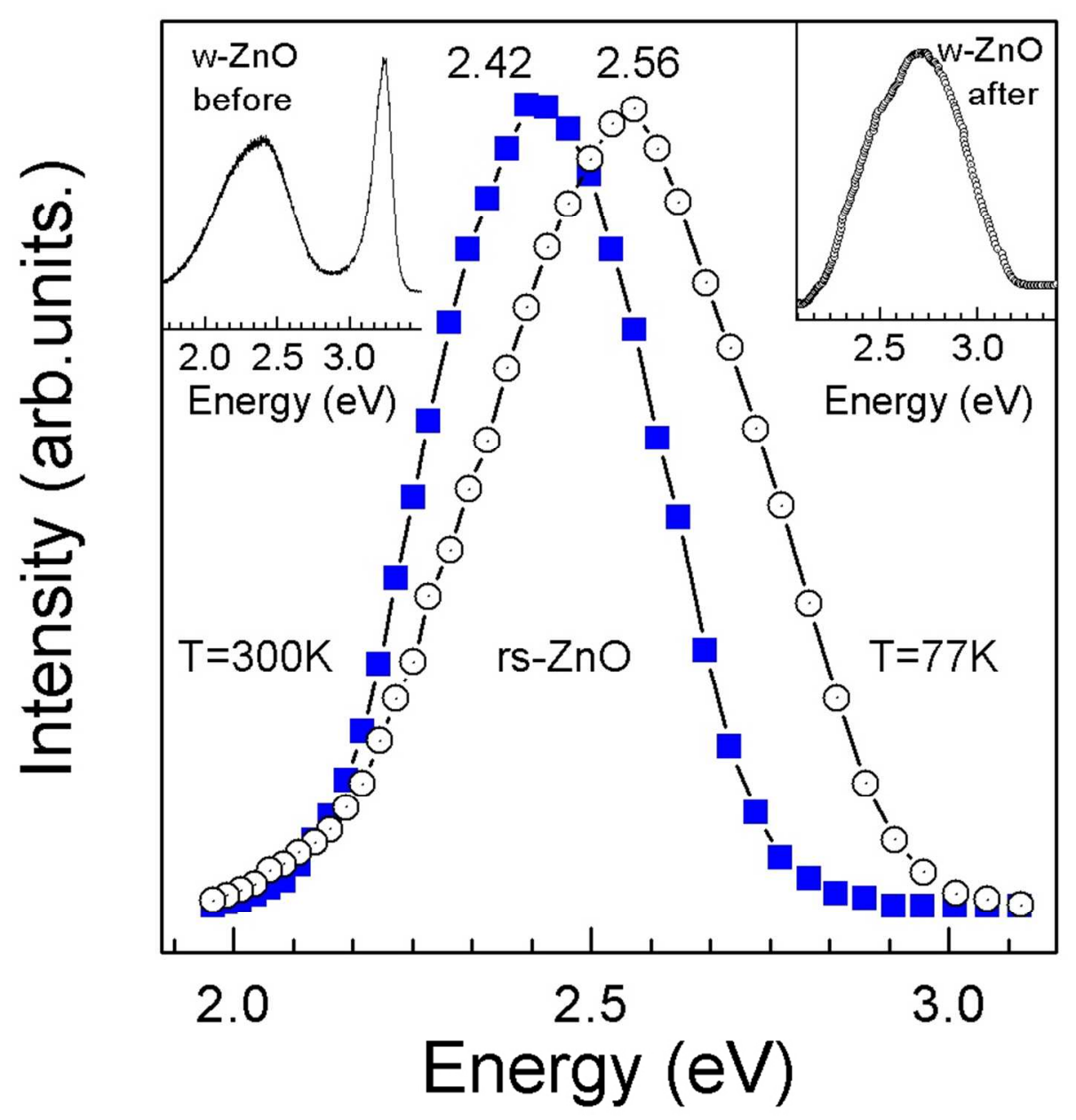

$84 \times 84 \mathrm{~mm}(300 \times 300$ DPI $)$ 


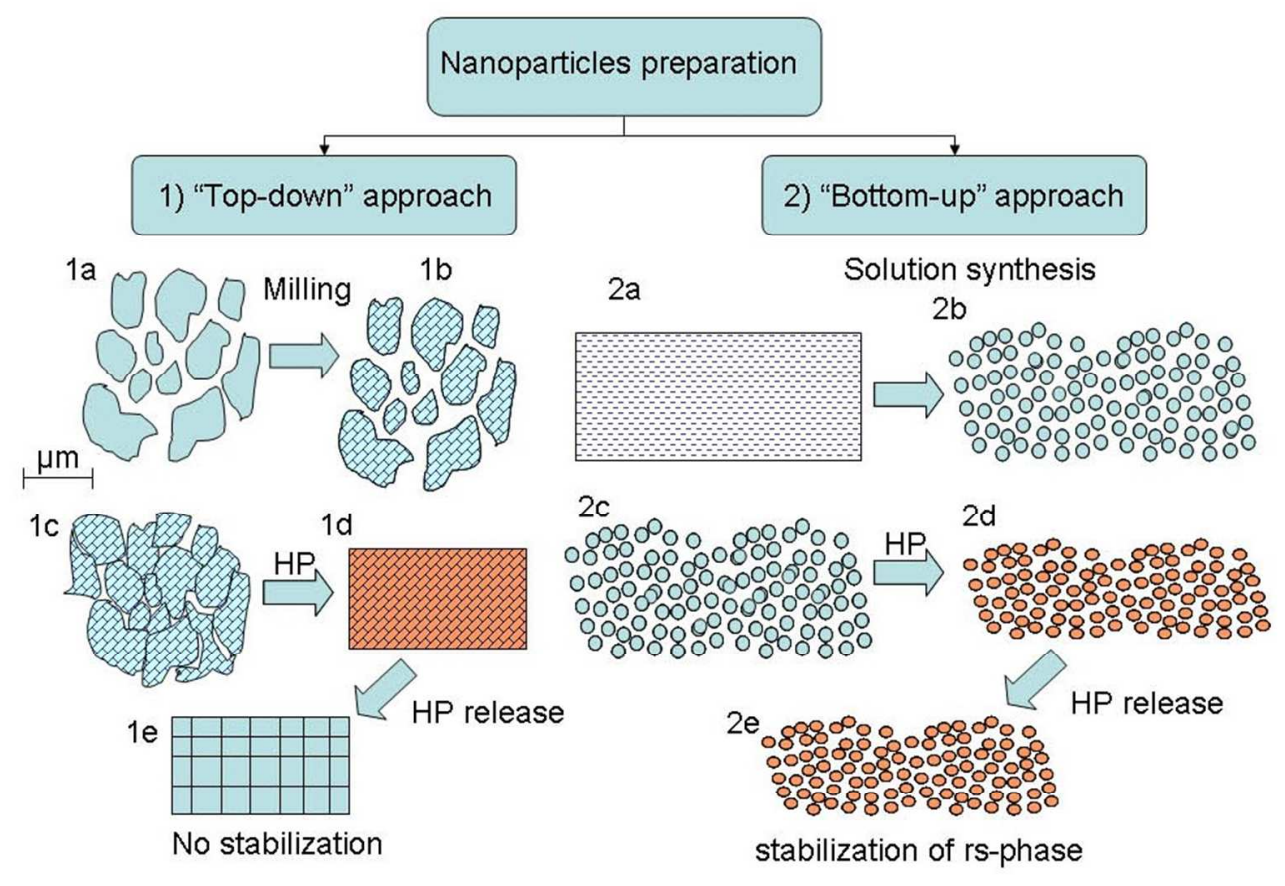

$84 \times 63 \mathrm{~mm}(300 \times 300$ DPI $)$ 


\title{
Nanocrystallinity as a Route to Metastable Phases: Rock Salt ZnO
}

\author{
Andrey N. Baranov, ${ }^{\dagger} *$ Petr S. Sokolov, ${ }^{\ddagger}$ Viktor A. Tafeenko, ${ }^{\dagger}$ Christian Lathe, ${ }^{\|}$Yan V. Zubavichus, ${ }^{\S}$ \\ Aleksey A. Veligzhanin, ${ }^{\S}$ Mikhail V. Chukichev ${ }^{\dagger}$ and Vladimir L. Solozhenko \\ ${ }^{\dagger}$ Moscow State University, 119991 Moscow, Russia \\ \$LSPM-CNRS, Université Paris Nord, 93430 Villetaneuse, France

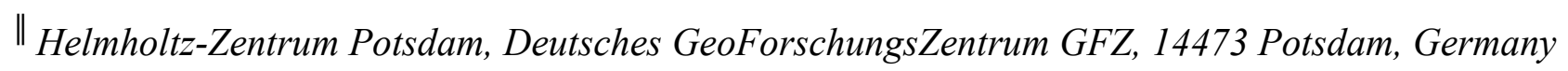

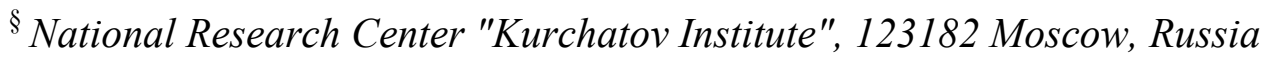

\begin{abstract}
RECEIVED DATE
* Tel: +7(495)9391083, Fax: +7(495)9390998, e-mail: anb@inorg.chem.msu.ru
\end{abstract}

\begin{abstract}
:
A synthesis route to rock-salt zinc oxide $(r s-\mathrm{ZnO})$, high-pressure phase metastable at ambient conditions, has been developed. High-purity bulk nanocrystalline $r s$ - $\mathrm{ZnO}$ has been synthesized from wurtzite $(w) \mathrm{ZnO}$ nanopowders at $7.7 \mathrm{GPa}$ and $770-820 \mathrm{~K}$ and for the first time recovered at normal conditions. Structure, phase composition and thermal phase stability of recovered $r s-\mathrm{ZnO}$ have been studied by synchrotron X-ray powder diffraction and X-ray absorption spectroscopy (XANES and EXAFS) at ambient pressure. Phase purity of $r s-\mathrm{ZnO}$ was achieved by usage of $w$ - $\mathrm{ZnO}$ nanoparticles with narrow size distribution as a pristine material synthesized by various chemical methods. At ambient pressure $r s-\mathrm{ZnO}$ could be stable up to $360 \mathrm{~K}$. The optical properties of $r s-\mathrm{ZnO}$ have been studied by conventional cathodoluminescence in high vacuum at room and liquid-nitrogen temperatures. The nanocrystalline $r s-\mathrm{ZnO}$ at 300 and $77 \mathrm{~K}$ has shown bright blue luminescence at 2.42 and $2.56 \mathrm{eV}$, respectively.
\end{abstract}

KEYWORDS cubic zinc oxide, nanocrystals, high-pressure synthesis, phase transition, luminescent properties. 


\section{INTRODUCTION}

Zinc oxide is a promising semiconductor due to its wide direct band gap $(3.37 \mathrm{eV}$ for $w-\mathrm{ZnO})$ and high exciton binding energy $(60 \mathrm{meV}) .{ }^{1,2} \mathrm{ZnO}$-based nanostructured materials are attractive for fabrication of optoelectronic devices in blue and ultraviolet spectral regions. At ambient conditions, the thermodynamically stable phase of $\mathrm{ZnO}$ has hexagonal wurtzite structure with 4-fold tetrahedral coordination ( $w$-ZnO phase, $\mathrm{P} 6_{3} \mathrm{mc}$ ). Similarly to other II-VI semiconductor compounds with wurtzite structure, at high pressure $w$ - $\mathrm{ZnO}$ undergoes phase transition into denser rock-salt structure with 6-fold coordination ( $r s-\mathrm{ZnO}$ phase, $\mathrm{Fm} 3 \mathrm{~m})^{3,4}$ that is promising for optoelectronics applications due to its ability to incorporate much higher concentration of dopants as compared to wurtzite $\mathrm{ZnO}{ }^{2,5}$

At room temperature phase transition of $w-\mathrm{ZnO}$ into $r s-\mathrm{ZnO}$ occurs at about $9 \mathrm{GPa} .{ }^{6-11}$ The transition pressure depends both on temperature ${ }^{6,7}$ and grain size. ${ }^{8-10}$ Upon decompression at room temperature, the reverse transition of as-synthesized microcrystalline $r s-\mathrm{ZnO}$ into $w$ - $\mathrm{ZnO}$ takes place at $\sim 2 \mathrm{GPa}$, that renders impossible to recover single-phase $r s-\mathrm{ZnO}$ at ambient conditions. ${ }^{7-11}$

The formation of $r s-\mathrm{ZnO}$ from nanocrystalline $w$ - $\mathrm{ZnO}$ occurs at much higher $(>9 \mathrm{GPa})$ pressures that was explained by the significant contribution of surface energy. ${ }^{8-10}$ For instance, $w$-ZnO with particles size of $12 \mathrm{~nm}$ undergoes phase transition at $\sim 15 \mathrm{GPa}^{8}$. Decremps et al. ${ }^{12}$ and Bayarjargal et al. ${ }^{13}$ claimed quenching of nanocrystalline $r s-\mathrm{ZnO}$ synthesized in a diamond anvil cell (DAC). However, the authors did not mention whether the samples were recovered from DAC (and subsequently from the gasket) or were studied just inside the cell. In the latter case, samples should preserve some strains that produce small but considerable residual pressure sufficient for the stabilization of $r s-\mathrm{ZnO}$. Very recently, however, it has been clearly shown that recovery of single-phase nanocrystalline $r s$-ZnO from DAC is not possible. $^{14}$

Metastable rock salt $\mathrm{Me}$ II $\mathrm{O}-\mathrm{ZnO}\left(\mathrm{Me}^{\mathrm{II}}=\mathrm{Mg}^{2+}, \mathrm{Ni}^{2+}, \mathrm{Fe}^{2+}, \mathrm{Co}^{2+}, \mathrm{Mn}^{2+}\right)^{15,16}$ and $\mathrm{LiMe}^{\mathrm{III}} \mathrm{O}_{2}-\mathrm{ZnO}$ $\left(\mathrm{Me}^{\mathrm{III}}=\mathrm{Fe}^{3+}, \mathrm{Ti}^{3+}\right)$ solid solutions with high (up to 0.8 molar fraction) $\mathrm{ZnO}$ content can be recovered 
from $1400-1600 \mathrm{~K}$ and pressures above $7 \mathrm{GPa}$ due to the stabilization effect of foreign cations, as described previously. ${ }^{17}$ The use of oxide ${ }^{18}$ and salt ${ }^{19}$ matrixes also allows one to recover metastable $r s-$ $\mathrm{ZnO}$ nanocrystals by quenching from high $(>7 \mathrm{GPa})$ pressure and high $(\sim 800 \mathrm{~K})$ temperature.

Here we report of the first synthesis of pure nanocrystalline bulk $r s-\mathrm{ZnO}$ in a large volume highpressure apparatus by quenching from $\sim 7.7 \mathrm{GPa}$ and $\sim 800 \mathrm{~K}$ and the study of structure, thermal stability and cathodoluminescence properties of this phase at ambient pressure.

\section{EXPERIMENTAL SECTION}

Starting materials. Since the size effect can be efficiently exploited only when particles with uniform and narrow size distribution are used, for preparation of the starting $w$ - $\mathrm{ZnO}$ nanopowders we have chosen three chemical techniques that allow producing nanoparticles with a narrow grain size distribution, i.e. zinc oxide precipitation from $\mathrm{Zn}\left(\mathrm{CH}_{3} \mathrm{COO}\right)_{2}$ alcohol solutions, ${ }^{20,21,22}$ thermal decomposition of $\mathrm{ZnO}_{2}$ zinc peroxide ${ }^{23}$ and thermal decomposition of $\mathrm{Zn}\left(\mathrm{CH}_{3} \mathrm{COO}\right)_{2}$ diethyleneglycol solutions. $^{24,25}$ The experimental details can be found in Supporting Information.

The synthesized $w$ - ZnO nanopowders have been studied by scanning (SEM) and transmission (TEM) electron microscopy, X-ray diffraction (XRD) and surface area measurements (BET). The characteristic SEM and TEM images of starting $w$-ZnO powders are given in Fig.1 (TEM image of sample NP1) and Fig. S1 (TEM or SEM images of other samples) in Supporting Information. The X-ray diffraction patterns of starting $w$-ZnO powders are also presented in Supporting Information (Fig. S2). We emphasize that the particle size determined by TEM or SEM could be almost the same as crystallite size calculated from XRD data (line broadening) but at larger sizes the difference is obvious (see Table 1). 
High-pressure synthesis. High-pressure experiments have been carried out using a toroid-type $\operatorname{apparatus}^{26}$ (5-8 GPa, quenching experiments, gold capsules) at LSPM-CNRS (Villetaneuse, France) and MAX200x multianvil press ${ }^{27}$ (8-15 GPa, in situ studies and quenching experiments, MgO pressure medium and BN capsules) at HASYLAB-DESY (Hamburg, Germany). The experimental details are described elsewhere. ${ }^{16}$ Powdered samples were preliminary compacted to tablets, placed inside capsules, then gradually compressed up to required pressure, heated at desired temperature (770-820 K) for $10-$ $15 \mathrm{~min}$, then quenched by switching off the power and slowly decompressed. After pressure release the bulk samples were recovered from high-pressure cell and studied at ambient pressure (Supporting Information, Table 1).

Characterization. Phase composition of recovered samples has been studied by powder X-ray diffraction using MZIII Seifert $(\mathrm{Cu} \mathrm{K} \alpha$ radiation) and G3000 TEXT Inel ( $\mathrm{Cu} \mathrm{K} \alpha 1$ radiation) diffractometers. Synchrotron powder X-ray diffraction measurements $(\lambda=0.69797 \AA)$ have been performed at beamlines B2 (HASYLAB-DESY) and 1711 (MAX-lab); Debye-Scherrer geometry with rotating quartz capillary was used. FullProf software ${ }^{28}$ has been used for profile analysis and refinement procedure; the details of data processing are described elsewhere. ${ }^{29}$ The powder diffraction patterns have been analyzed using the Le Bail method ${ }^{30}$ to obtain the best values of lattice parameters and crystallite size.

The specific surface area of $w$-ZnO powders was calculated according to the Brunauer-Emmett-Teller (BET) method from nitrogen adsorption isotherms (Nova 4200e device, Quantachrome Instruments).

The particle size and micromorphology of synthesized $w$-ZnO nanopowders have been studied using a LEO 912 AB (Carl Zeiss) transmission electron microscope and LEO Supra 50 VP (Carl Zeiss) highresolution scanning electron microscope. High resolution transmission electron microscopy (HRTEM) images, selected area electron diffraction (SAED) patterns were recorded on a JEOL JEM-2100 microscope. 
The thermal stability of as-synthesized $r s-\mathrm{ZnO}$ nanocrystalline bulks has been in situ studied by angledispersive X-ray diffraction and X-ray absorption spectroscopy (XANES and EXAFS) at Structural Materials Science beamline, Kurchatov Synchrotron Radiation Center (Moscow). ${ }^{31}$ High-temperature X-ray diffraction measurements have been performed using a bent linear gas detector in the transmission geometry $(\lambda=0.826561 \AA)$ upon stepwise heating up to $400 \mathrm{~K}$ with an acquisition time of 5 min per pattern. Before each data collection the sample temperature was stabilized for $10 \mathrm{~min}$. Zn K-edge X-ray absorption spectra have been measured in transmission mode using $\mathrm{Si}(111)$ channel-cut monochromator and two ionization chambers filled with appropriate $\mathrm{N}_{2}$-Ar mixtures. Processing of EXAFS spectra was performed using IFEFFIT software ${ }^{32}$ with $a b$ initio phase and amplitude functions from FEFF8. ${ }^{33}$ The latter code was also used to simulate Zn K-edge XANES spectra of both $r s-\mathrm{ZnO}$ and $w$-ZnO within the full-multiple-scattering approach. The calculation was performed similar to that in ${ }^{11}$ but the probe cluster was extended up to $8 \AA$ (about 200 atoms).

The cathodoluminescence (CL) measurements have been performed using the original setup ${ }^{34}$ equipped with the pulsed "electron gun" and vacuum cryostat $\left(5 \times 10^{-7} \mathrm{~mm} \mathrm{Hg}\right)$. The cryostat chamber has a vacuum-tight transparent window that allows one to observe the luminescence from the sample. The spectra were recorded using a diffraction grating spectrometer (dispersion $5 \AA / \mathrm{mm}$ ) and synchronous detector at temperatures of 77 and $300 \mathrm{~K}$. The current and energy were varied within the ranges of $0.05-2 \mathrm{~mA}$ and $10-50 \mathrm{keV}$, respectively.

\section{RESULTS \\ High-pressure synthesis and recovery of single-phase rs- $\mathrm{ZnO}$}

At room temperature compression of $w-\mathrm{ZnO}$ nanopowder with the smallest $(\sim 8 \mathrm{~nm})$ particle size (NP1) up to $15 \mathrm{GPa}$ in the MAX200x multianvil press does not result in formation of the rock salt phase, and X-ray diffraction patterns show only reflections of pristine nanocrystalline $w$-ZnO (See Fig.S3 in Supporting information). Upon heating at $15 \mathrm{GPa}$, the lines of $r s-\mathrm{ZnO}$ appear in the diffraction 
patterns starting with $600 \mathrm{~K}$, and the total disappearance of $w-\mathrm{ZnO}$ reflections is observed at $\sim 800 \mathrm{~K}$. Similar behavior has been observed at lower pressures, down to $8 \mathrm{GPa}$, both in multianvil and toroidtype high-pressure apparatuses.

Here we observed an apparent extension of the phase transition hysteresis, viz., and the direct transition occurs at RT at pressure higher than $15 \mathrm{GPa}$ that by far exceeds the value of $9 \mathrm{GPa}$ usually observed for microcrystalline samples and we successfully achieved stabilization of the $r s-\mathrm{ZnO}$ phase after moderate heating, quenching and pressure release. As was established later in the quenching experiments upon temperature increase up to $770-820 \mathrm{~K}$ the transition pressure came down and $7.7 \mathrm{GPa}$ is a sufficient pressure value for the $r s-\mathrm{ZnO}$ phase stabilization. At the same time higher temperatures could lead to the intensification of diffusion processes $^{35}$ and consequently to the sintering and coarsening of nanoparticles.

The $w$-ZnO powders (NP2-NP6, SMP, MP) with larger grain sizes (from $14 \mathrm{~nm}$ to $\sim 1 \mu \mathrm{m}$ ) were treated at the same $p-T$ conditions $(7.7 \mathrm{GPa}$ and $\sim 800 \mathrm{~K})$ using toroid-type apparatus. The as-synthesized single-phase $r s-\mathrm{ZnO}$ is quenchable and can be recovered at ambient conditions in the bulk form with at least $5 \mathrm{~mm}$ in diameter (See TOC). The results of X-ray phase analysis for recovered samples are summarized in Fig. S4 and Table in Supporting Information. Samples NP1-NP5 showed rock salt crystalline structure without $w$-ZnO impurity peaks, but samples NP6, SMP and MP showed a mixture of two phases. We may conclude that there is the critical crystallite size $(45 \mathrm{~nm})$ of pristine $w$ - $\mathrm{ZnO}$ above which the $100 \%$ recovery is not possible. It was also experimentally established that the presence of microcrystalline particles in starting nanocrystalline $w$ - $\mathrm{ZnO}$ sample leads to the appearance of $w$ - $\mathrm{ZnO}$ impurity peaks in diffraction patterns of recovered $r s-\mathrm{ZnO}$.

Fig. 2 shows a characteristic powder X-ray diffraction pattern of $r s-\mathrm{ZnO}$ (NP2) taken at ambient conditions. Rietveld refinement has shown that the recovered samples are single-phase, and observed reflections can be indexed in the NaCl-type crystal structure (Fm3m space group, $a=4.2813 \AA$, $R_{p}=0.03$ ). Lattice parameters for all single phase samples (NP1-NP5) vary from 4.2807 to $4.2863 \AA$, and it is important to note that average crystallite sizes of rs-ZnO phase determined from XRD line 
broadening are very close for all samples studied $(28-44 \mathrm{~nm})$ irrespective of the crystallite size of starting w-ZnO nanoparticles (see Table in Supporting information).

The HRTEM images of the recovered $r s-\mathrm{ZnO}$ (Fig. 3) exhibits domains (Fig.3b) of a different size with well-ordered cubic structure separated by high angle grain boundaries probably inherited from initial $w$-ZnO nanoparticles. The indexing of the fast Fourier transform (FFT) (top-left inset in Fig. 3a) and the SAED pattern (bottom-right inset in Fig. 3a) of the HRTEM image are consistent with rock salt structure as revealed by the XRD. Thus the sample has a rock-salt structure with the lattice parameter $\mathrm{a}=0.43(1) \mathrm{nm}$. This value is in agreement, within experimental error, with that obtained by XRD technique. SEM images of the synthesized samples (not shown here) typically demonstrate submicrocrystalline structure with cracks and pores, and grain size below $50 \mathrm{~nm}$. Summarizing the electron microscopy and XRD data for NP1-NP5 samples, we can conclude that all of them are quite similar being the true bulk material with nanocrystalline grains of approximately the same size.

\section{Stability of bulk nanocrystalline rs- $\mathrm{ZnO}$}

At normal conditions bulk samples of nanocrystalline $r s-\mathrm{ZnO}$ do not show any tendency to phase transition into $w$ - $\mathrm{ZnO}$ for at least 1 year. However, intensive grinding of the sample promotes the reverse phase transition, and as-formed fine powder completely converts into $w$ - $\mathrm{ZnO}$ within $2-4$ weeks. Besides, even a small amount of the initial microcrystalline $w-\mathrm{ZnO}$ remaining in the quenched samples leads to relatively fast degradation of $r s$-phase.

Thermal stability of the recovered $r s-\mathrm{ZnO}$ at ambient pressure has been studied by high-temperature synchrotron X-ray diffraction. The diffraction patterns of single-phase nanocrystalline $r s-\mathrm{ZnO}$ (NP3, $a=4.280(4) \AA$ ) taken at ambient pressure upon stepwise heating are shown in Fig. 4 . At $\mathrm{T}=333 \mathrm{~K}$, the changes become evident: a new series of peaks typical of $w-\mathrm{ZnO}$ emerges. The transformation virtually completes at $393 \mathrm{~K}$. The as-formed $w$-ZnO has lattice parameters of $a=3.242(3)$ and $c=5.224(4) \AA$ and crystallite size about $10 \mathrm{~nm}$, that was estimated from diffraction peaks profile analysis. For other samples we observed the similar behavior upon heating. For example, reverse phase transition of the samples NP2 and NP5 occurs in the temperature range of 340-400 K and 350-370 K, respectively. 
A further insight into the details of local structure of nanocrystalline $r s-\mathrm{ZnO}$ and its thermally-driven transformation into $w$-ZnO can be obtained from X-ray absorption spectroscopy (XANES and EXAFS). The $\mathrm{Zn} \mathrm{K}$ edge XANES spectra of the samples studied are shown in Fig. 5. The spectra of the $r s-\mathrm{ZnO}$ and $w-\mathrm{ZnO}$ are distinctly different that reflects different coordination environments of $\mathrm{Zn}$ atoms therein, viz., octahedral and tetrahedral, respectively. Both spectra (see Fig. 5) reveal a pre-edge shoulder $A$ at ca. $9670 \mathrm{eV}$, the main absorption band $B$ at ca. $9675 \mathrm{eV}$, which appears to split into two components for $r s-\mathrm{ZnO}$, and post-edge peaks $C$ and $D$. The peak $C$ for $r s-\mathrm{ZnO}$ is shifted by about $6 \mathrm{eV}$ to higher energies with respect to $w-\mathrm{ZnO}$, whereas, peak $D$ reveals distinct "wiggle" structure. All these spectral features are nicely reproduced in theoretical simulation. It is worth noting that the spectrum of $r s-\mathrm{ZnO}$ after heat treatment is quite similar to that of reference $w$-ZnO but retains some subtle differences, which probably reflects its disordered nanostructured nature.

EXAFS data are shown in Fig. 6. Fourier transforms (FT) of both $r s-\mathrm{ZnO}$ and $w-\mathrm{ZnO}$ are dominated by $\mathrm{Zn}-\mathrm{O}$ and $\mathrm{Zn} . . \mathrm{Zn}$ contributions. However, in the rock salt structure, the $\mathrm{Zn}-\mathrm{O}$ corresponds to the longer distance while $\mathrm{Zn} . . \mathrm{Zn}$ to the shorter one. Local-structure parameters calculated from the experimental EXAFS spectra by non-linear fitting procedure with $a b$ initio theoretical amplitude and phase functions are summarized in Table 2. The Zn...Zn distance of $3.03 \AA$ obtained from EXAFS refinement for $r s-\mathrm{ZnO}$ corresponds to the cubic lattice parameter of $4.285 \AA$ in fair agreement with X-ray diffraction data. In the case of the $r s-\mathrm{ZnO}$ sample after heat treatment to $393 \mathrm{~K}$, the structural parameters are close to those for crystalline $w$ - $\mathrm{ZnO}$ reference, although intensities of FT peaks are somewhat diminished probably indicative of specific to nanocrystalline state atomic disorder.

\section{Cathodoluminescence studies of $r s-\mathrm{ZnO}$}

The CL spectra of the $r s-\mathrm{ZnO}$ (at $300 \mathrm{~K}$ and $77 \mathrm{~K}$ ) and room temperature CL spectra of $w$ - $\mathrm{ZnO}$ (pristine nanopowders and after reverse transition) for the sample NP5 are presented in Fig. 7 (for other samples we observed similar spectra). The CL spectrum of the $w$-ZnO pristine nanopowders in the left inset consists of intense, near-band-edge (NBE), ultraviolet emission with a maximum at $3.22 \mathrm{eV}$ and a 
full width at half maximum (FWHM) of $134 \mathrm{meV}$ and a broad defect-related green band with some lower intensity near $2.34 \mathrm{eV}$, having a FWHM of $750 \mathrm{meV}$. In contrast, the CL spectrum of the $r s-\mathrm{ZnO}$ at $300 \mathrm{~K}$ consists of a broad NBE band with maximum at $2.42 \mathrm{eV}$ and FWHM of $420 \mathrm{meV}$. The asymmetry of the peaks at $300 \mathrm{~K}$ and $77 \mathrm{~K}$ could be explained by the fluctuations of borders of the band gap (Urbach rule), greater fluctuations are observed for conduction band border, since the effective mass of the holes is higher than the effective mass of the electrons. The broadening of low-temperature peak in comparison with $300 \mathrm{~K}$ peak indicates the absence of nonequilibrium free charge carriers and their bound state on defects.

After the annealing at $473 \mathrm{~K}$ for 2 hours the spectrum of $r s-\mathrm{ZnO}$ sample drastically changes due to reverse transition ( $r s-\mathrm{ZnO}$ to $w-\mathrm{ZnO}$ ). The spectrum (right inset) consists of intense broadband with maximum at $2.43 \mathrm{eV}$ and this spectral position is independent of temperature. The absence of characteristic NBE peak of $w-\mathrm{ZnO}$ in the UV-range can be attributed to the high concentration of defects in the sample resulted from the phase transformation of initial nanocrystalline $r s-\mathrm{ZnO}$ at relatively low temperatures. The wavelength maximum of $r s-\mathrm{ZnO}$ at $300 \mathrm{~K}$ is independent on electron beam current (power of excitation) and time delay that means that donor-acceptor pairs do not contribute to the luminescence and this peak can be attributed to the NBE emission. The broadness of the peak could be explained by nano-crystallinity of the sample and perhaps residual strain in the recovered sample.

Band gap of $r s-\mathrm{ZnO}$ can be estimated as $2.42 \pm 0.06 \mathrm{eV}$ at $300 \mathrm{~K}$ and $2.56 \pm 0.15 \mathrm{eV}$ at $77 \mathrm{~K}$. The observed temperature dependence of band gap (coefficient is $-0.63 \pm 0.5 \mathrm{meV} / \mathrm{K}$ ) indicates that the emission might be attributed to the NBE transition rather than intra-center luminescence. Luminescence intensity decreases according to exponential law with $\tau=0.75 \pm 0.03 \mathrm{mks}$.

\section{DISCUSSION}

Nanocrystallinity plays a decisive role for $r s-\mathrm{ZnO}$ phase stabilization. It is well known that there are two general approaches for nanoparticles preparation - i) "top-down" (milling, for example) and ii) "bottom-up" (solution synthesis). Previously ${ }^{8,12}, w$-ZnO nanopowders for high-pressure experiments 
were prepared by grinding $\mathrm{ZnO}$ microcrystalline powders in a ball mill, and mean crystallite size of 12(2) nm was estimated from X-ray line broadening. Usually, long grinding time is accompanied not only with reduction of mean grain (crystallite) size but also with enhancement of strain $^{36}$, formation of point, linear and planar defects ${ }^{37}$ and structural and composition irregularities during plastic deformation $^{38-40}$. Besides, the sample exposed to long-time grinding is unavoidably contaminated by material of balls and/or a vial ${ }^{8,41,42}$. All the factors can greatly influence to recoverability of $r s-\mathrm{ZnO}$ after pressure release. Whereas $w$ - $\mathrm{ZnO}$ nanopowders obtained by "chemical techniques" in the current work are completely free from these problems.

Another example of "top-down" way for nanocrystallinity was described in the work ${ }^{43}$, where nanocrystalline $w$ - $\mathrm{ZnO}$ with grain size of $17 \mathrm{~nm}$ was obtained starting from single crystal $w$ - $\mathrm{ZnO}$ by high pressure treatment at $13 \mathrm{GPa}$ and $500 \mathrm{~K}$. Reverse phase transformation $r s-\mathrm{ZnO} \rightarrow w-\mathrm{ZnO}$ occurring at room temperature after pressure release was responsible for nanocrystallinity. We have performed similar experiments in order to check the possibility of $r s$-phase stabilization after repeated high pressure and temperature treatment of microcrystalline $\mathrm{ZnO}$ powder at $7.7 \mathrm{GPa}$ and $800 \mathrm{~K}$. At the first treatment nanocrystalline sample with (crystallite size was $17 \pm 4 \mathrm{~nm})^{35}$ was obtained, but after the second experiment at high pressure and temperature no traces of $r s$ - $\mathrm{ZnO}$ phase were detected in the diffraction pattern.

Our experimental results and literature data of two ways of $r s-\mathrm{ZnO}$ phase stabilization were summarized in the form of a scheme (Fig. 8). In the left part of the scheme ("top-down" approach) the evolution of pristine microcrystalline powder during all the four stages of milling, compacting, high pressure treatment and pressure releasing is presented. At the first stage $(1 \mathrm{a} \rightarrow \mathrm{b})$, milling of initial microcrystalline powder leads to the ensemble of polydisperse particles with nanometer scale crystallites. As-obtained powder can be easily compacted with rather high "green" density $(1 \mathrm{~b} \rightarrow \mathrm{c})$. Pressure induced phase transition occurs $(1 \mathrm{c} \rightarrow \mathrm{d})$, while grain reorientation and alignment promote the crystallite growth even at moderate temperature. After pressure release in a large volume high pressure apparatus quenching the $r s$-phase is not observed as a result of reverse $r s$ to $w$-phase transition $(1 \mathrm{~d} \rightarrow \mathrm{e})$. 
In our work we have used the second ("bottom-up") approach allowing us to obtain ensemble of nanopowders with narrow particle size distribution without microcrystalline impurities $(2 \mathrm{a} \rightarrow \mathrm{b})$. In this case nanoparticle size (TEM data) is equal to crystallite size (XRD data) (Fig. 1-2, Table 1). Tablets prepared for high pressure treatment by compacting this kind of powders typically have low "green" density (less than $70 \%)(2 \mathrm{~b} \rightarrow \mathrm{c})$. At high pressure and moderate temperatures $(\leq 800 \mathrm{~K})$ we did not observe substantial grain (crystallite) growth in accordance with XRD measurements in situ neither for the pristine w-phase nor for $r s$-phase after phase transition $(2 \mathrm{c} \rightarrow \mathrm{d})$. After pressure release XRD measurements for the recovered samples exhibit only single $r s$-phase without impurities $(2 \mathrm{~d} \rightarrow \mathrm{e})$.

Obviously in the first case (milling microcrystalline powder or pressure treatment of single crystals) formation of nanosized crystallites is not accompanied by formation of phase boundaries, instead of that intergrain boundaries will not contribute significantly into the increase of free energy. Furthermore reverse phase transition will not be restricted at intergrain boundaries compared to interparticle point contacts. Micron sized particles more likely revert at pressure release to $w$-ZnO due to possibility of spontaneous intragrain nucleation that is suppressed in the case of individual nanoparticle.

The crucial role of nanocrystalline size at phase transition at high pressure was previously discussed by Alivisatios with co-workers in the work ${ }^{44}$. It was illustrated that surface energy can play a dominant role in determining the relative stability of structural nanocrystalline phases and must be taken into consideration in studies of nanocrystal structural phase changes.

The rocksalt structure of $\mathrm{ZnO}$ nanocrystals, in analogy with "bottom-up" approach, should have higher surface energy because the shape changes accompanying the transformation alter the crystallographic facets. In analogy with the known shape changes for the CdSe nanocrystals described previously we may suggest that these exposed faces in the rocksalt structure should be predominantly the (111) faces parallel to the crystallographic c axis, and these are a particularly high-energy faces. So the effect of metastability of $r s-\mathrm{ZnO}$ phase after pressure release could be revealed only for nanocrystals with open surface that is realized in the right way of Figure 8. Noting the important role of the surface in the kinetic stabilization of the metastable rs- $\mathrm{ZnO}$ phase it is necessary to analyze its condition, in particular, 
the role of surface (stabilizing?) groups. In the first case, these are hydroxyl groups, which may be present on the surface of all the samples. Furthermore, in spite of prolonged annealing (see Supporting information), we can not completely exclude the presence of residual organic groups from zinc acetate (precursor) on the surface of samples NP1-NP4, except for the sample NP5 which was obtained by decomposition of zinc peroxide. Obviously the role of the surface and especially surface passivating groups should be studied in more details in future.

\section{CONCLUSIONS}

As a result of the present study, we have shown that the $r s-\mathrm{ZnO}$ can be obtained by the high-pressure treatment $(7.7 \mathrm{GPa}$ and $\sim 800 \mathrm{~K}$ ) in the form of nanocrystalline bulks with up to one cubic centimeter in volume. Provided that starting $w$ - $\mathrm{ZnO}$ powders prepared via chemical methods have narrow particle size distribution, crystallite size therein does not exceed $45 \mathrm{~nm}$, and no impurity of micrometer-sized particles are present, the $r s-\mathrm{ZnO}$ phase can be reproducibly recovered at ambient pressure and temperature and persist for at least several months. The reverse phase transition to the thermodynamically stable $w$ - ZnO phase is initiated by mild heating. Luminescent properties of $r s-\mathrm{ZnO}$ reported for the first time indicate a narrower bandgap $(2.42 \mathrm{eV}$ at $300 \mathrm{~K})$ as compared to $w$-ZnO. All rs$\mathrm{ZnO}$ samples, regardless of the size of the initial $\mathrm{w} \mathrm{ZnO}$ nanoparticles exhibit similar microstructure and luminescent properties.

\section{ACKNOWLEDGMENTS}

The authors thank O. Kapitanova for PAS/PAEAS synthesis, Drs. T. Chauveau, A.M.T Bell and C. Gundlach for assistance in X-ray diffraction studies, Dr. A. Vyacheslavov for BET measurements, and Dr. V. Mukhanov for helpful discussions. X-ray diffraction studies with synchrotron radiation at W2 and B2 beamlines (HASYLAB-DESY) have been carried out during beamtime allocated to Project DESY-D-I-20100021 EC and received funding from the European Community's Seventh Framework Programme (FP7/2007-2013) under grant agreement n² 226716. Synchrotron X-ray powder diffraction experiments at beamline 1711 (MAX-lab) has been performed during beamtime allocated to Proposal \# 
20110330. This work was supported by the Russian Foundation for Basic Research (Project No 11-0301124). Synchrotron radiation experiments at the Kurchatov Synchrotron Radiation Source were supported in part under Russian Federal Contract No. 16.552.11.7055. PSS is grateful to the "Science and Engineering for Advanced Materials and Devices" (SEAM) Lab of Excellence for financial support. 


\section{REFERENCES}

1. Pearton, S. J.; Norton, D. P.; Ip, K.; Heo, Y. W.; Steiner, T. Progr. Mater. Sci. 2005, 50, 293.

2. Ozgur, U.; Alivov, Ya. I.; Liu, C.; Teke, A.; Reshchikov, M. A.; Dogan, S.; Avrutin, V.; Cho, S.-J.; Morkoc, H. J. Appl. Phys. 2005, 98, 041301.

3. Mujica, A.; Rubio, A.; Munoz, A.; Needs, R. J. Rev. Mod. Phys. 2003, 75, 863.

4. Bates, C. H.; White, W. B.; Roy, R. Science 1962, 137, 993.

5. Janotti, A.; Van de Walle, C.G. Rep. Prog. Phys. 2009, 72, 126501.

6. Kusaba, K.; Syono, Y.; Kikegawa, T. Proc. Japan Acad. Ser. B 1999, 75, 1.

7. Decremps, F.; Zhang, J.; Liebermann, R. C. Europhys.Lett. 2000, 51, 268.

8. Jiang, J. Z.; Olsen, J. S.; Gerward, L.; Frost, D.; Rubie, D.; Peyronneau, J. Europhys. Lett. 2000, 50, 48 .

9. Kumar, R. S.; Cornelius, A.L.; Nicol, A. F. Current Appl. Phys. 2007, 7, 135.

10. Grzanka, E.; Gierlotka, S.; Stelmakh, S.; Palosz, B.; Strachowski, T.; Swiderska-Srode, A.; Kalisz, G.; Lojkowski, W.; Porsch F. Z. Kristallogr. 2006, 23, 337.

11. Decremps, F.; Datchi, F.; Saitta, A. M.; Polian, A.; Pascarelli, S.; Di Cicco, A.; Itie, J. P.; Baudelet, F. Phys. Rev. B. 2003, 68, 104101.

12. Decremps, F.; Pellicer-Porres, J.; Datchi, F.; Itie, J. P.; Polian, A.; Baudelet, F.; Jiang, J. Z. Appl. Phys. Lett. 2002, 81, 4820.

13. Bayarjargal, L.; Winkler, B.; Haussuhl, E.; Boehler, B. Appl. Phys. Lett. 2009, 95, 061907.

14. Dong, Z.; Zhuravlev, K. K.; Morin, A. S.; Li, L.; Jin, S.; Song Y. J. Phys. Chem. C 2012, 116, 2102.

15. Baranov, A. N.; Solozhenko, V. L.; Chateau, C.; Bocquillon, G.; Petitet, J. P.; Panin, G. N.; Kang, T. W.; Shpanchenko, R. V.; Antipov, E. V.; Oh, Y. J. J. Phys.: Cond. Matter 2005, 17,3377

16. Baranov, A. N.; Sokolov, P. S.; Kurakevich, O. O.; Tafeenko, V. A.; Trots, D.; Solozhenko, V. L. High Press. Res. 2008, 28, 515.

17. Sokolov, P. S.; Baranov, A. N.; Tafeenko, V. A.; Solozhenko, V. L. High Press. Res. 2011, 31, 304.

18. Baranov, A. N.; Kurakevych, O. O.; Tafeenko, V. A.; Sokolov, P. S.; Panin, G. N.; Solozhenko, V. L. J. Appl.Phys. 2010, 107, 073519.

19. Sokolov, P. S.; Baranov, A. N.; Dobrohotova, Z. V.; Solozhenko, V. L. Rus. Chem. Bull. 2010, 59, 325.

20. Meulenkamp, E. A. J. Phys. Chem. B 1998, 102, 5566.

21. Baranov, A. N.; Kapitanova, O. O.; Panin, G. N.; Kang, T. V. Russ. J. Inorg. Chem. 2008, $53,1366$. 
22. CaO, H. L.; Qian, X. F.; Gong, Q.; Du, W. M.; Ma, X. D.; Zhu, Z. K. Nanotechnology 2006, 17,3632 .

23. Chen, W.; Lu, Y. H.; Wang, M.; Kroner, L.; Paul, H.; Fecht, H.-J.; Bernarcik, J.; Stahl, K.; Zhang, Z. L.; Wiedwald, U.; Kaiser, U.; Ziemann, P.; Kikegawa, T.; Wu, C. D.; Jiang, J. Z. J. Phys. Chem. C 2009, 113, 1320.

24. Duan, J.; Huang, X.; Wang, E . Mater. Lett. 2006, 60, 1918.

25. Seeling, E. W.; Yamilov, A.; Cao, H.; Chang R. P. H. Mater. Chem. Phys. 2003, 80, 257.

26. Khvostantsev, L. G.; Slesarev, V. N.; Brazhkin, V. V. High Press. Res. 2004, 24, 371.

27. Lathe, C.; Muller, H. J.; Schilling, F. R.; Reichmann, H. J.; Lauterjung, J. Synch. Rad. In Nat. Sci. 2006, 5, 111.

28. Rodriguez-Carvajal J. Physica B 1993, 192, 55.

29. Gurskii, S. I.; Tafeenko, V. A.; Baranov A. N. Rus. J. Inorg. Chem. 2008, 53, 111.

30. Le Bail, A.; Duroy, H.; Fourquet J. L. Mat. Res. Bull. 1988, 23, 447.

31. Chernyshov, A. A; Veligzhanin, A. A.; Zubavichus, Y. V. Nucl. Instr. Meth. Phys. Res. A 2009, 603, 95.

32. Ravel, B.; Newville, M. J. Synchr. Rad. 2005, 12, 537.

33. Zabinsky, S. I.; Rehr, J. J.; Ankudinov, A.; Albers, R. C.; Eller, M. J. Phys. Rev. B 1995, 52, 2995.

34. Braga, É. S.; Gaugash, P. V.; Drozhzhov, Yu. P.; Ivanova, G. N.; Kas'yan, V. A.; Nedeoglo D. D.; Chukichev M. V. J. Appl. Spectrosc. 1981, 35, 1277.

35. Solozhenko, V. L.; Kurakevich, O. O.; Sokolov, P. S.; Baranov, A. N. J. Phys. Chem. A 2011, 115, 4354.

36. Dutta, S.; Chattopadhyay, S.; Sutradhar, M.; Sarkar, A.; Chakrabarti, M.; Sanyal, D.; Jana, D. J. Phys. Condens. Matter 2007, 19, 236218.

37. Radoi, R.; Fernandez, P.; Piqueras, J.; Wiggins, M. S.; Solis, J. Nanotechnology 2003, 14, 794.

38. Tay, Y. Y.; Li, S.; Sun, C. Q.; Chen, P. Appl. Phys. Lett. 2006, 88, 173118.

39. Lang, M.; Zhang, F.; Zhang J.; Wang, J.; Schuster, B.; Trautmann, C.; Neumann, R.; Becker, U.; Ewing, R. C. Nature Materials 2009, 8, 793.

40. Zhang, F. X.; Wang, J. W.; Lian, J.; Lang, M. K.; Becker, U.; Ewing, R. C. Phys. Rev. Lett. 2008, 100, 045503.

41. Lao, Y. W.; Kuo, S. T.; Tuan, W. H. Ceram. Int. 2008, 35, 1317.

42. Vojisavljevic, K.; Scepanovic, M.; Sreckovic, T.; Crujic-Brojcin, M.; Brankovic, Z.; Brankovic, G. J. Phys. Condens. Matter 2008, 20, 475202.

43. Gonzalez, J.; Marquina, J.; Rodriguez, F.; Valiente, R. High Press. Res. 2009, $29,594$.

44. Jacobs, K.; Wickham, J.; Alivisatos, A. P. J. Phys. Chem. B 2002, 106, 3760. 


\section{TABLES}

Table 1. Results of electron microscopy and XRD analysis of starting $w$ - $\mathrm{ZnO}$ nanopowders

\begin{tabular}{|c|c|c|c|c|c|}
\hline \multirow{2}{*}{ Sample } & \multirow{2}{*}{$\begin{array}{l}\text { Synthetic } \\
\text { technique* }\end{array}$} & \multirow{2}{*}{$\begin{array}{l}\text { Average particle } \\
\text { size from SEM } \\
\text { and/or TEM (nm) }\end{array}$} & \multirow{2}{*}{$\begin{array}{l}\text { Average crystallite } \\
\text { size from XRD data } \\
(\mathrm{nm})\end{array}$} & \multicolumn{2}{|c|}{ Lattice parameter $(\AA)$} \\
\hline & & & & $a$-axis & $c$-axis \\
\hline $\mathrm{NP} 1^{\dagger}$ & PAS & $8(1)$ & $9(1)$ & $3.2542(8)$ & $5.201(2)$ \\
\hline $\mathrm{NP} 2^{\dagger}$ & PAS & $14(3)$ & $16(3)$ & $3.254(1)$ & $5.208(4)$ \\
\hline NP3 & PAEAS & $16(3)$ & $18(3)$ & $3.2515(7)$ & $5.2095(2)$ \\
\hline NP4 & PAEAS & $15-25$ & $18(3)$ & $3.2524(5)$ & $5.211(2)$ \\
\hline NP5 & TDZP & $123(55)$ & $11(2)$ & $3.2536(8)$ & $5.214(5)$ \\
\hline NP6 & TDPEGS & $200(40) / 85(10) \star$ & $45(5)$ & $3.2557(3)$ & $5.2158(9)$ \\
\hline SMP & TDDEGS & $150(70)$ & $>50$ & $3.2517(2)$ & $5.2101(6)$ \\
\hline MP\| & & $<1 \mu \mathrm{m}$ & - & $3.2524(1)$ & $5.2110(7)$ \\
\hline
\end{tabular}

* PAS - precipitation from alcohol solutions ${ }^{20,21}$

PAEAS - precipitation from alcohol (excess of alkali) solutions ${ }^{22}$

TDZP - thermal decomposition of zinc peroxide $\left(\mathrm{ZnO}_{2}\right)^{23}$

TDPEGS - thermal decomposition of $\mathrm{Zn}\left(\mathrm{CH}_{3} \mathrm{COO}\right)_{2}$ polyethyleneglycol solutions ${ }^{24}$

TDDEGS - thermal decomposition of $\mathrm{Zn}\left(\mathrm{CH}_{3} \mathrm{COO}\right)_{2}$ diethyleneglycol solutions ${ }^{25}$

$\dagger \quad$ The BET surface areas of NP1 and NP2 powders are $5200 \pm 400$ and $3200 \pm 400$, respectively, that are much larger than the surface area of MP ${ }^{\|}$sample - microcrystalline ZnO powder (Alfa Aesar, 99.99\%, 325 mesh, surface area of $500 \pm 100 \mathrm{~m}^{2} / \mathrm{mole}$ ).

The particle shape is ellipsoid-like with average length $\sim 200 \mathrm{~nm}$, and traverse diameter $\sim 85 \mathrm{~nm}$. 
Table 2. Local-structure parameters around $\mathrm{Zn}$ atoms in the recovered $r s-\mathrm{ZnO}$ sample, products of its thermal transformation at $393 \mathrm{~K}$ and reference $w$-ZnO sample from Zn K-edge EXAFS data

\begin{tabular}{|c|c|c|c|c|}
\hline Sample & Sphere & $\mathrm{N}$ & $\mathrm{R}, \AA$ & $\sigma^{2}, \AA^{2}$ \\
\hline \multirow{3}{*}{$\begin{array}{l}\text { recovered } \\
r s-\mathrm{ZnO}\end{array}$} & $\mathrm{Zn}-\mathrm{O}$ & 6 & 2.09 & 0.0103 \\
\hline & $\mathrm{Zn} \ldots \mathrm{Zn}$ & 12 & 3.03 & 0.0096 \\
\hline & $\mathrm{Zn} \ldots \mathrm{O}$ & 8 & 3.60 & 0.0131 \\
\hline \multirow{3}{*}{$\begin{array}{l}r s-\mathrm{ZnO} \text { after } \\
393 \mathrm{~K}\end{array}$} & $\mathrm{Zn}-\mathrm{O}$ & 4 & 1.97 & 0.0047 \\
\hline & $\mathrm{Zn} \ldots \mathrm{Zn}$ & 12 & 3.23 & 0.0104 \\
\hline & $\mathrm{Zn} \ldots \mathrm{O}$ & 9 & 3.77 & 0.0088 \\
\hline \multirow{3}{*}{$w-\mathrm{ZnO} *$} & $\mathrm{Zn}-\mathrm{O}$ & 4 & 1.97 & 0.0042 \\
\hline & $\mathrm{Zn} \ldots \mathrm{Zn}$ & 12 & 3.22 & 0.0094 \\
\hline & $\mathrm{Zn} . . . \mathrm{O}$ & 9 & 3.75 & 0.0072 \\
\hline
\end{tabular}

* Reference sample (MP) w-ZnO (see Table 1). 


\section{CAPTIONS FOR FIGURES}

Figure 1. TEM image of $w$-ZnO nanopowder (NP1). Right inset - SAED pattern, left inset particle size distribution.

Figure 2. Experimental (circles), calculated (red solid line) and difference (blue solid line) X-ray diffraction pattern $(\lambda=1.540598 \AA$ ) of the nanocrystalline $r s-\mathrm{ZnO}$ (NP2) quenched from $7.7 \mathrm{GPa}$ and $\sim 800 \mathrm{~K}$. Vertical bars indicate the calculated Braggs peaks position for $r s-\mathrm{ZnO}$.

Figure 3. a) HRTEM image of recovered nanocrystalline $r s$-ZnO (NP1) Upper left inset - FFT image, lower right inset - SAED pattern, b) HRTEM image of domains.

Figure 4. Diffraction patterns of nanocrystalline $r s-\mathrm{ZnO}$ (NP2) collected in situ upon stepwise heating. Indexes for $r s-\mathrm{ZnO}$ are shown in the bottom while indexes for $w-\mathrm{ZnO}$ are shown on the top.

Figure 5. Experimental (left) and simulated (right) XANES spectra for ZnO with the cubic rock-salt (NP5) and hexagonal wurtzite structures.

Figure 6. Left: experimental (black) and best-fit (red) Fourier transforms of Zn K-edge EXAFS spectra. Right: experimental EXAFS oscillations.

Figure 7. Center - RT (left) and 77-K (right) CL spectra of bulk nanocrystalline $r s-Z n O$ (NP5) synthesized at $8 \mathrm{GPa}$ and $800 \mathrm{~K}$. Left inset - the starting $w-Z n O$ nanopowder; right inset - CL spectra of the $w-Z n O$ sample obtained by annealing of $r s-Z n O$ at $473 \mathrm{~K}$ for $2 \mathrm{~h}$.

Figure 8. Scheme of phase transitions in the case of 1) top-down (milling) and 2) bottom-up (solution synthesis) approaches to nanocrystals preparation

1a) Initial stage - micron sized particles

1b) After milling - ensemble of polydispersed particles (SEM) with nanometer scale crystallites (XRD) $($ SEM size $>$ XRD size)

1c) Easily compacted powders with high green density

1d) After high pressure treatment at room temperatures - phase transition to rs-phase

1e) After pressure release - reverse phase transition of rs to w-phase. No stabilization!

2a) Initial stage - solution (See Supplementary Information) 
2b) After synthesis - ensemble of nanoparticles with narrow size distribution (TEM size $\approx$ XRD size)

2c) Poorly compacted powders with low green density

2d) After high pressure treatment at moderate temperatures - phase transition to rs-phase

2e) After pressure release - stabilization of rs-phase 
FIGURES

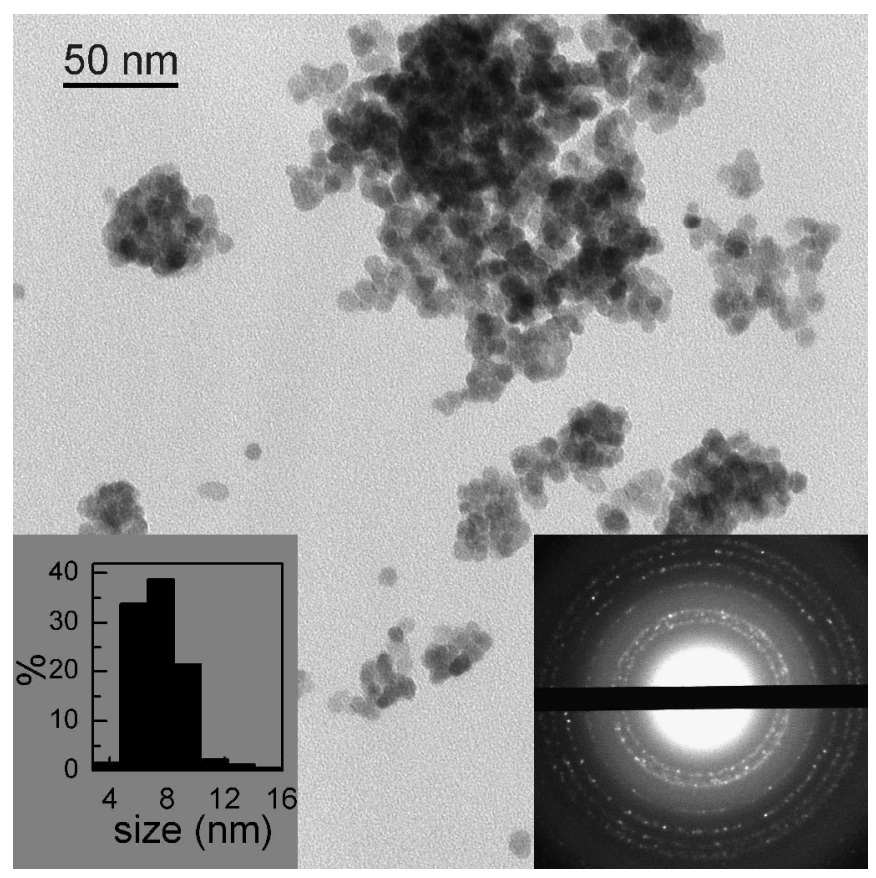

Figure 1.

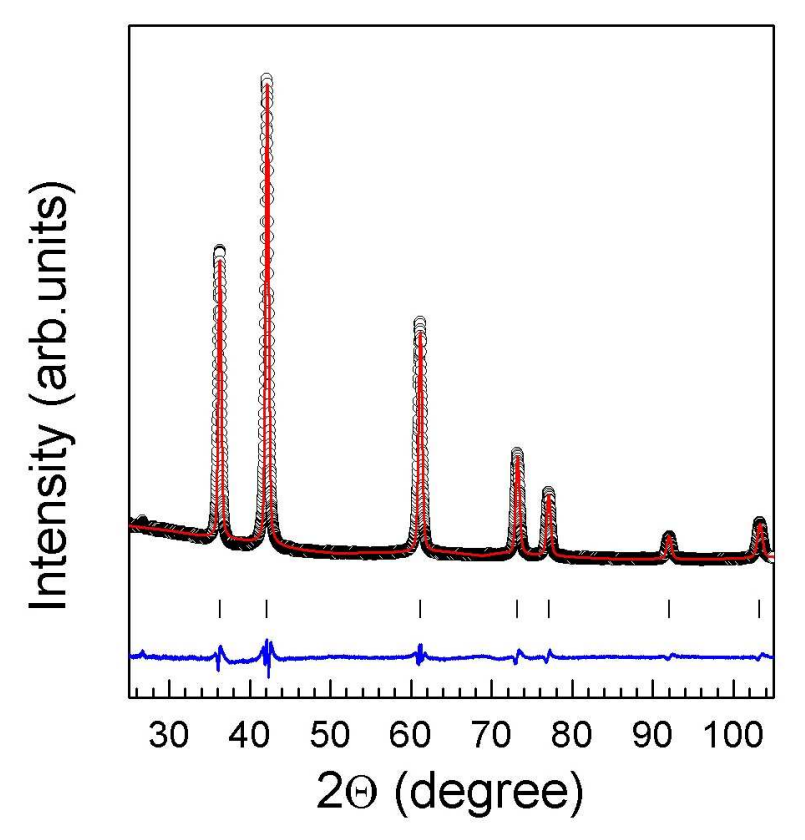

Figure 2. 


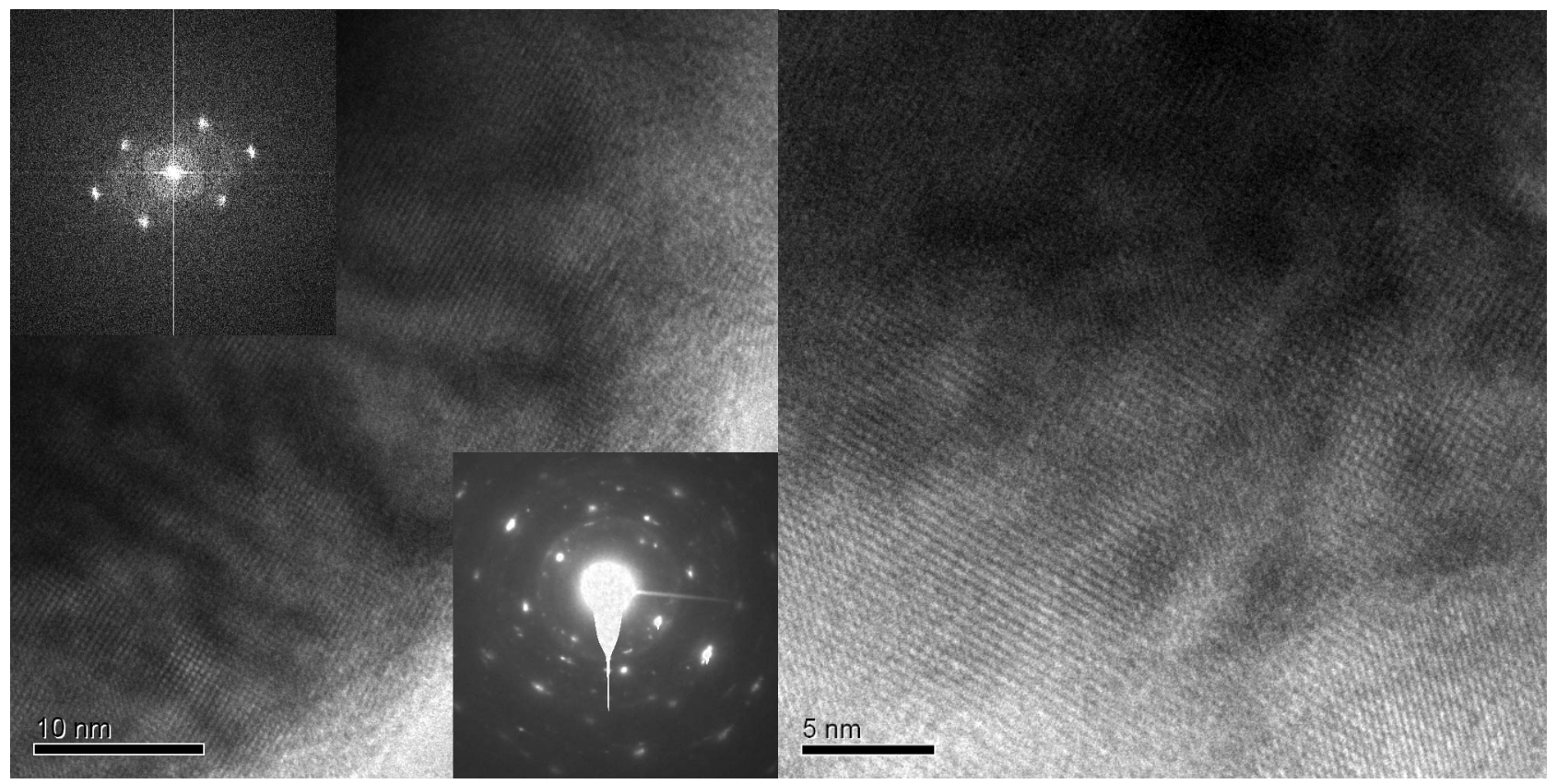

Figure 3.

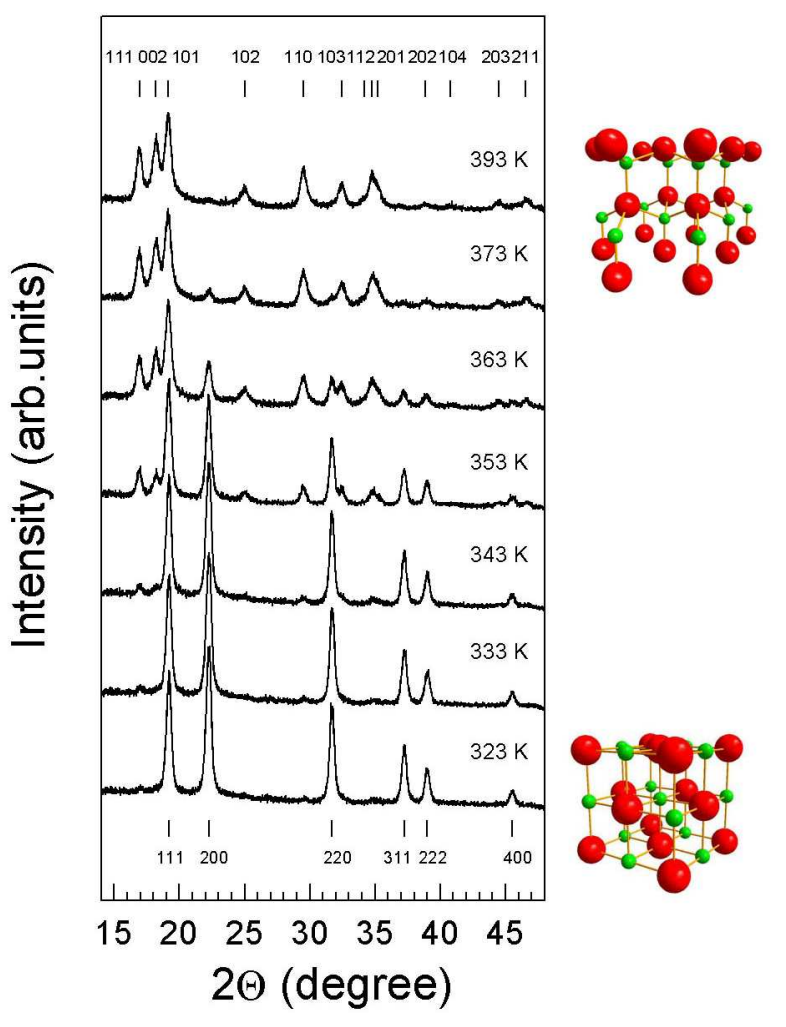

Figure 4. 


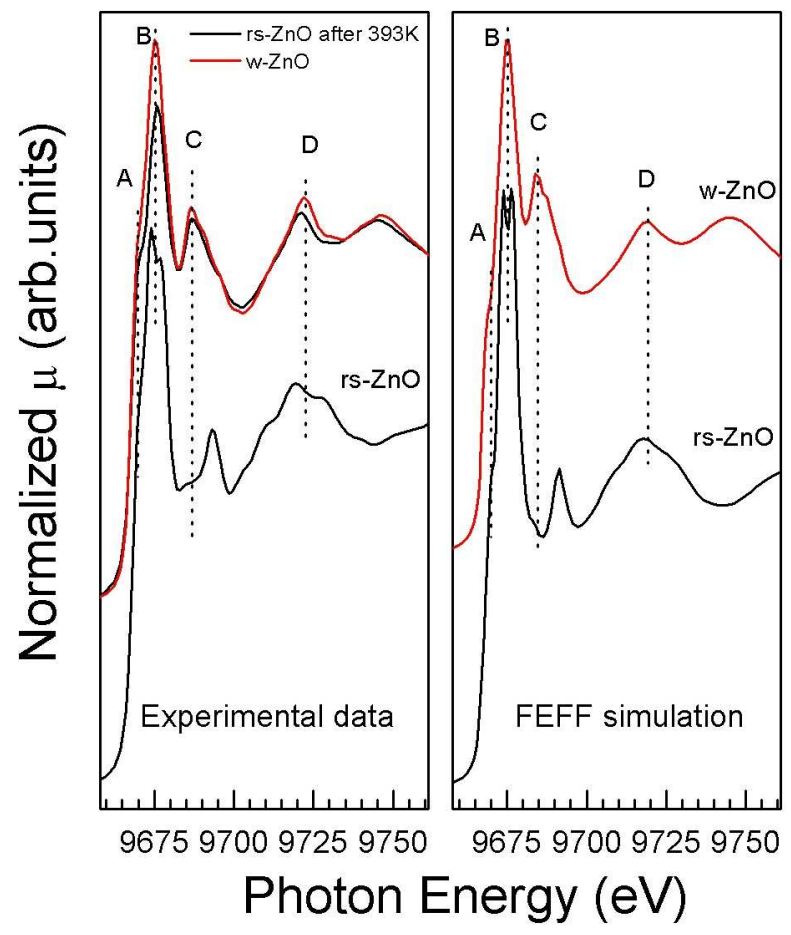

Figure 5.
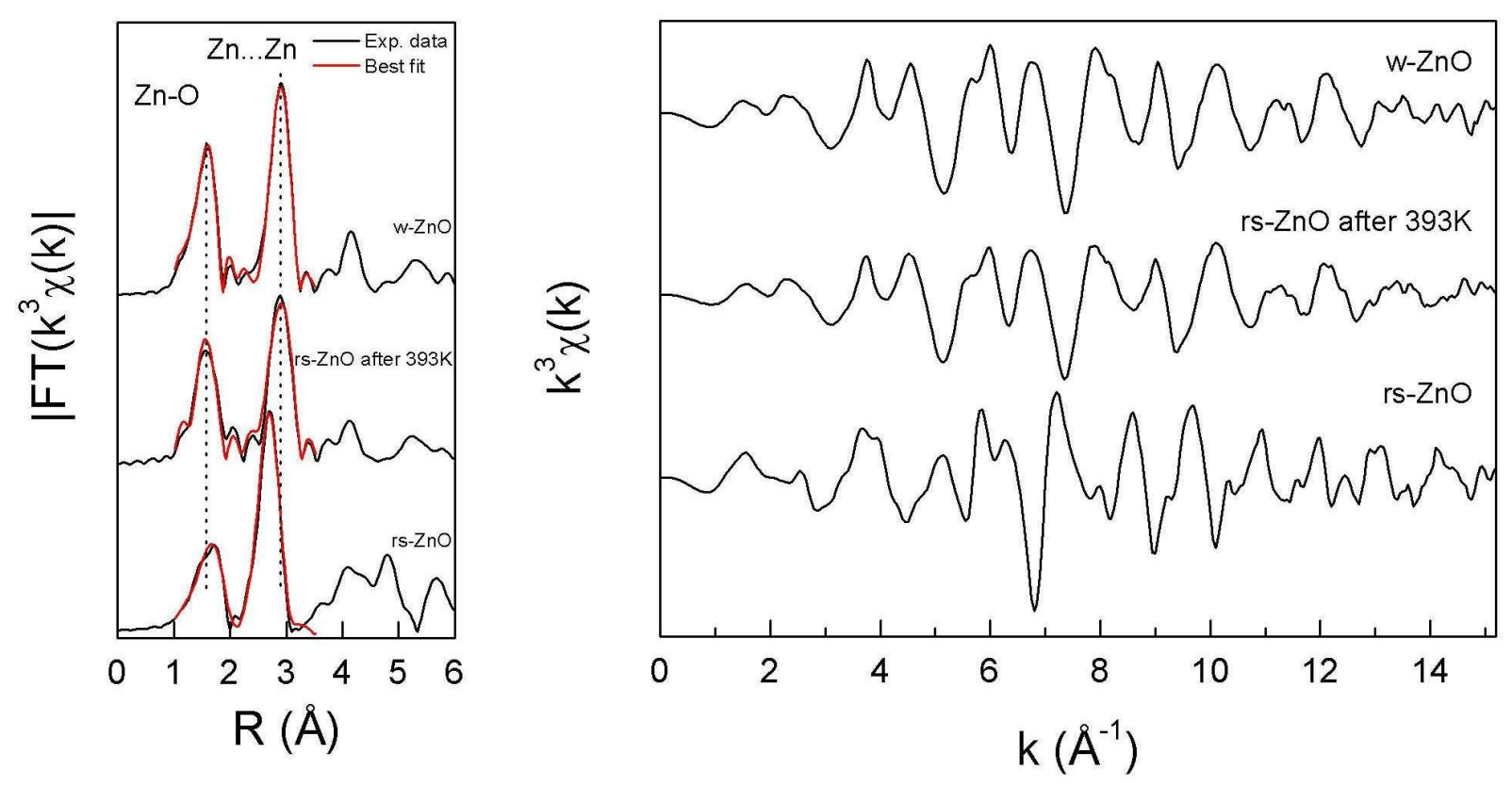

Figure 6. 


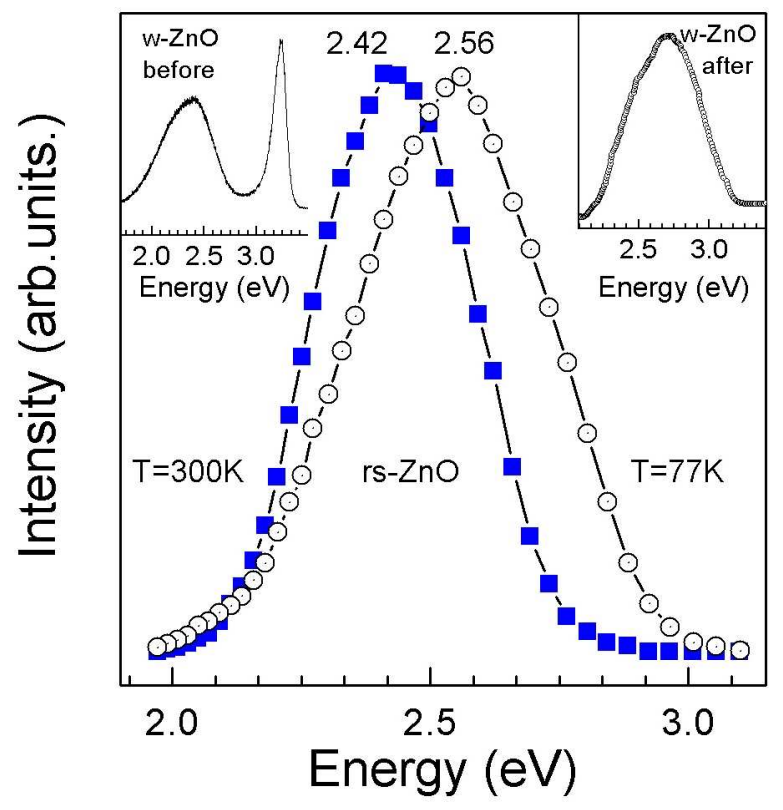

Figure 7.

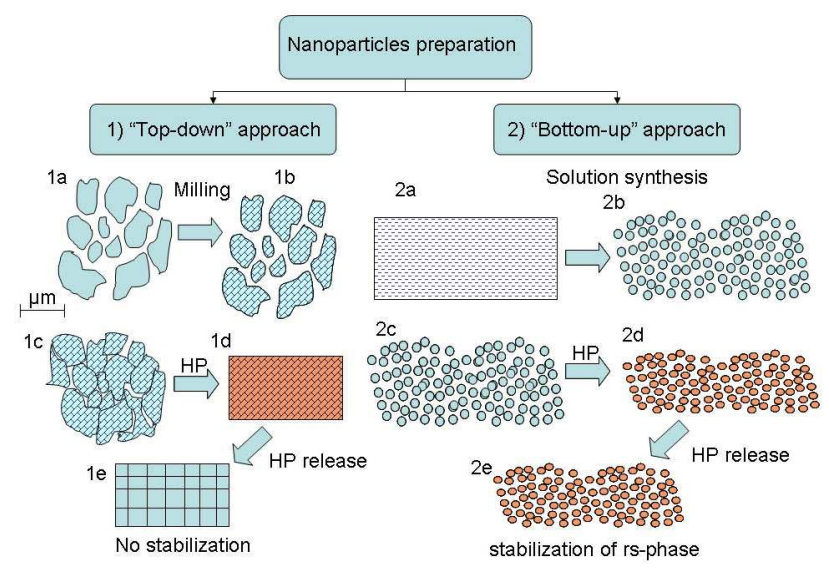

Figure 8 . 
For Table of Contents Use Only

2

3

4

5

6

7

8

9

10

11

12

13

14

15

16

17

18

19

20

21

22

23

24

25

26

27

28

29

30

31

32

33

34

35

36

37

38

39

40

41

42

43

44

45

46

47

48

49

50

51

52

53

54

55

56

57

58

59

60

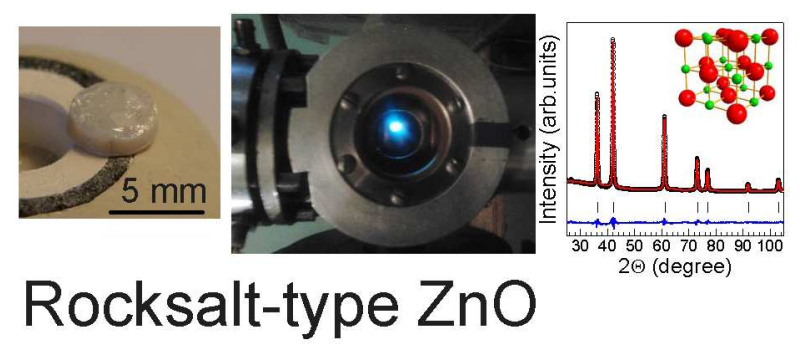




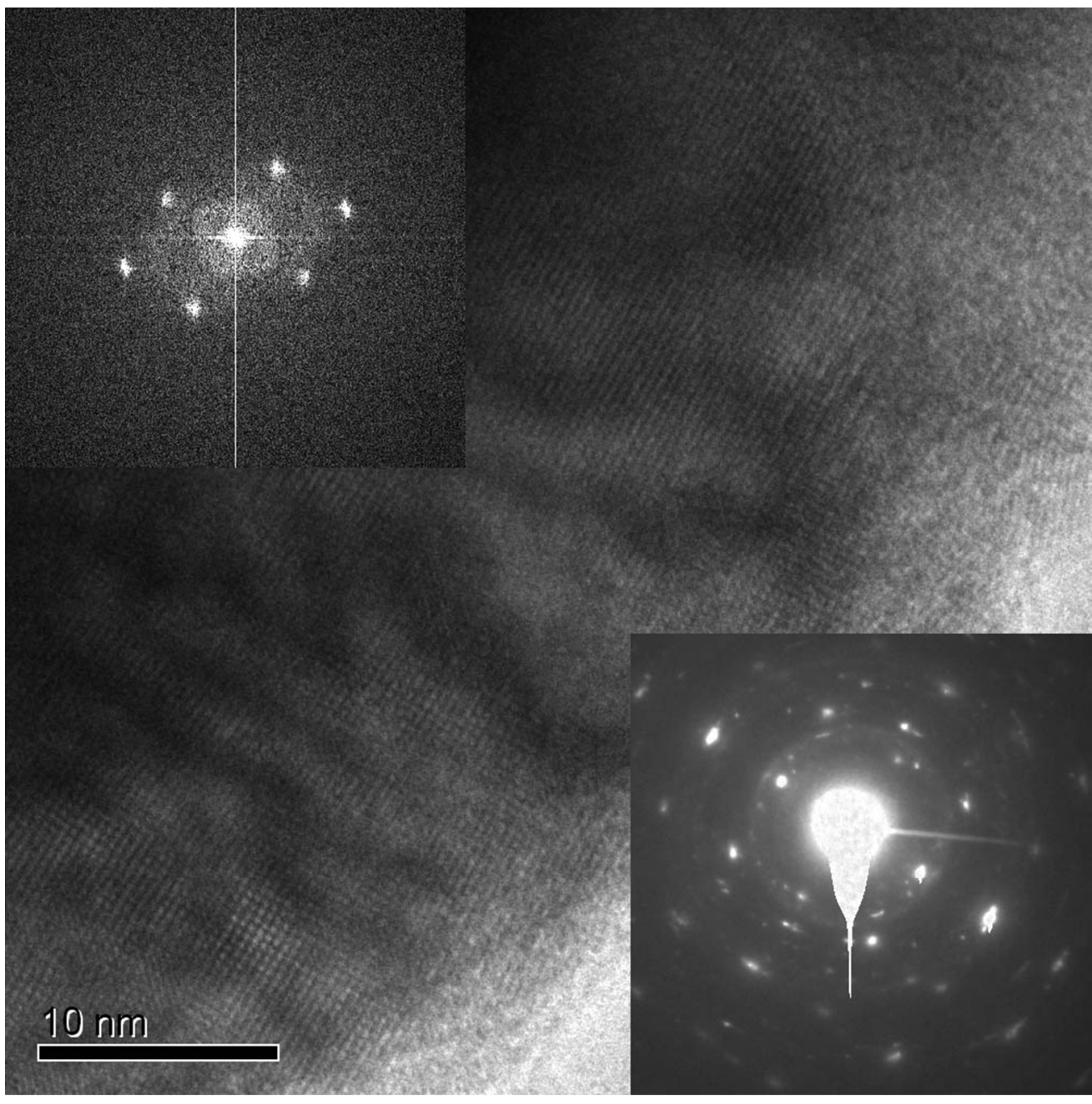

$84 \times 84 \mathrm{~mm}(300 \times 300$ DPI $)$ 


1
1
3
4
5
6
7
8
9
10
11
12
13
14
15
16
17
18
19
20
21
22
23
24
25
26
27
28
29
30
31
32
33
34
35
36
37
38
39
40
41
42
43
44
45
46
47
48
49
50
51
52
53
54
55
56
57
58
59
60

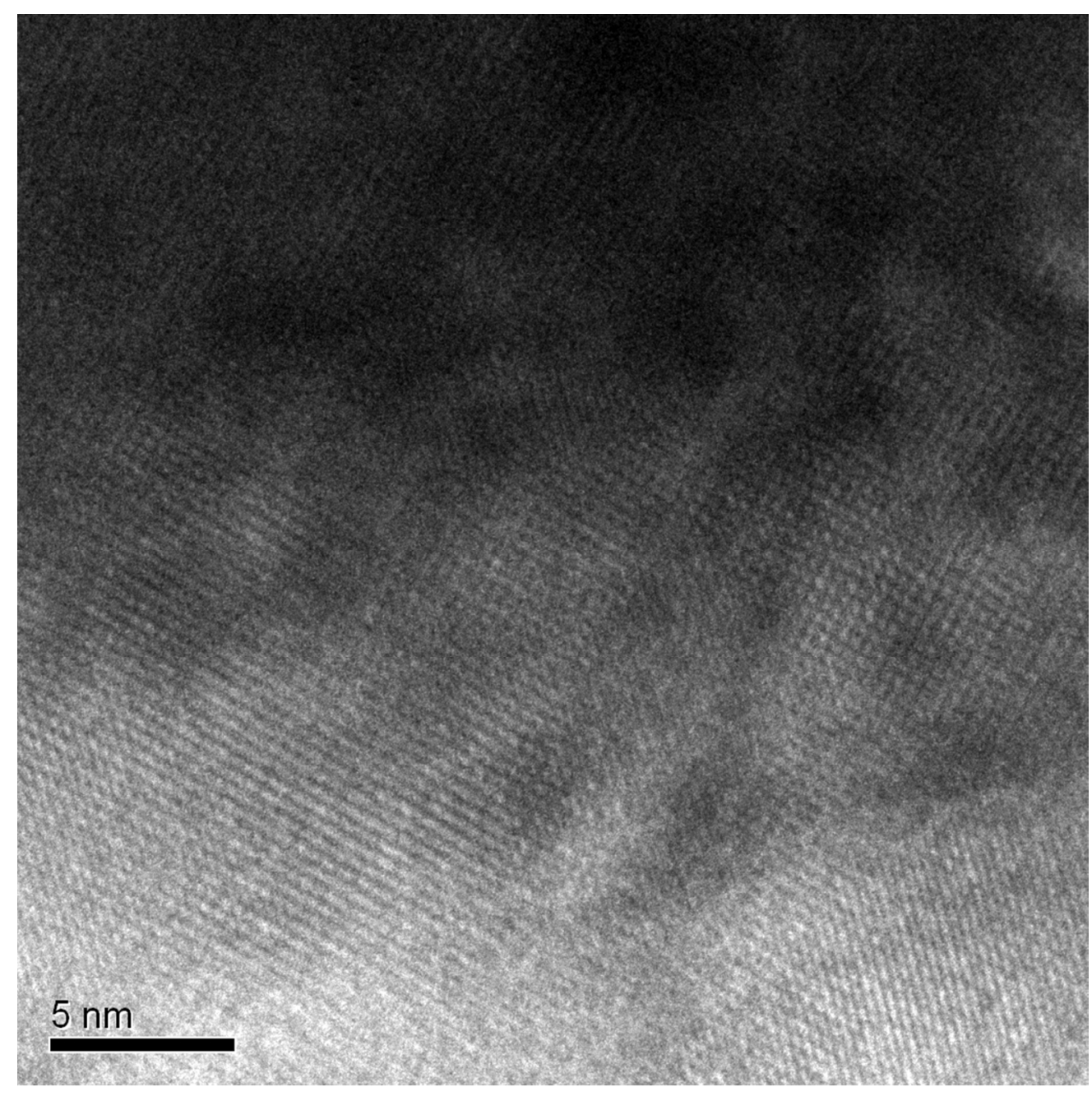

$366 \times 366 \mathrm{~mm}$ (71 x 71 DPI) 